\title{
Design of Peak Usage Time and Prediction Algorithm Based Battery Charging Technique
}

\author{
Mr. Mapari S.K. ${ }^{1}$, Prof. Borole Y.D. ${ }^{2}$ \\ ${ }^{I}$ Department of Electronics \& Telecommunication Engineering, G. H. Raisoni Institute of Engineering \& \\ Technology, Pune-412207, India. \\ ${ }^{2}$ Department of Electronics \& Telecommunication Engineering, G. H. Raisoni Institute of Engineering \& \\ Technology, Pune-412207, India.
}

\begin{abstract}
Solar resource is freely available so government is trying to implement the use of Solar panels as an energy source in rural and sub urban areas for lighting the street lights, but the battery used to store the power gets affected due to overcharging \& discharging. Charge controllers are usually installed in Solar Home Systems to protect batteries (from over charging and discharging) and to implement proper buck and boost charging techniques (e.g. Maximum Power Point Tracking etc.).Some MPPT controllers have also been developed to incorporate multiple charging sources (e.g. Main-Grid or PV panels) [3] [4]. However, these controllers lack proper charging techniques to ensure efficient use of multiple charging sources. Also due to improper charging algorithm there might be unnecessary or insufficient charging of batteries. This paper presents a design of peak usage time and prediction algorithm based battery charging technique which enables intelligent battery charging decisions [2]. And improve the battery life and efficiency of battery. Specifically, the system will use Mains charging only when Solar charging is insufficient. Also, the system will decide when to preserve battery and use Mains as direct drive loads. These decisions are made to utilize more solar energy and less Mains electricity while maintaining high reliability and improve efficiency. The decisions will be based upon battery's state which is calculated using various data such as peak usage time, solar voltage, solar current, load's power demand, batteries' specification etc. the system designed with this technique has better performance over other solar charge controllers.
\end{abstract}

Keywords: Solar System, PV panel, Peak usage time, prediction-based, hybrid charge controller

\section{Introduction}

Over the past few years solar systems are gaining popularity and it is one time investment. A solar system (SS) has an inverter, panels, batteries and charge controller [7] .Conventional electronic charge controllers for SS are generally installed to protect batteries, from overcharging / less charging and to implement proper charging based on peak usage time techniques. Some solar charge controllers have also been developed to incorporate multiple charging sources (e.g. Main Grid or PV panels) to charge batteries according to the availability of the sources. Though many implementation and ideas are being developed, there is still lack of appropriate algorithm for proper utilization of solar charging sources. Majority of the charging techniques developed till now basically deals with maximizing power utilization of a single source. However these techniques do not enable automatic charging decisions to ensure efficient use of solar or mains charge sources. For instance, these controllers do not decide when it is appropriate to charge battery using Mains (Main-Grid) in addition to Solar with peak usage time and battery state [1]. Due to lack of protection and decision, batteries in such places are either overcharge or less charged. For example, if the batteries are charged by Photo voltaic panels alone, it may not be sufficient during rainy days. This will create problem in continuous power supply. If the batteries are also charged by main line without any intelligent decision, then they may be unnecessarily charged battery. This will simply affect the battery life. This paper proposes a peak usage time and predictionbased algorithm which enables intelligent battery charging decisions based upon calculated battery's state and mains availability. The calculation is based upon several data such as solar voltage, solar energy availability, time schedule, battery specification, and load power demand and panel specification. Specifically, the system checks if solar charging alone is sufficient to charge battery to adequate level which will ensure reliability for certain time. If solar not sufficient, the controller employs Mains (if available) to charge the battery, thereby increasing the rate of charge. The system also makes other intelligent decisions according to climate condition for preserving battery, i.e. disconnecting or connecting battery as direct source to loads and connecting Mains as direct drive load. All these intelligent decisions are performed in order to maintain high efficiency while utilizing more solar energy and less Mains electricity. 


\section{Algorithm Description}

Flowchart of the prediction-based battery charging technique is shown in Fig. 1. In system the prediction algorithm is programmed and loaded to a processing unit such as microcontroller which then controls the charge controller [6]. As shown in the figure, the controller first requires various data such as solar energy availability time schedule, peak usage time, solar voltage and current, battery specification etc. It then calculates battery state using these data. The future time for the calculation can have different values it will changes according to time (e.g. 12 - 24 hours). There will be three Battery Conditions (BC) i.e. Excess, Sufficient and low. Determination of $\mathrm{BC}$ is further discussed in section 2.2. According to $\mathrm{BC}$, the master controller performs various battery charging operations. For this operation created algorithm in that different mode use. Depending on mode and peak usage time battery charging operation will take place. In all three cases, battery charging will take place via solar as well as Mains. Switching action controlled by controller. If battery condition is critical and solar is not available then charging takes place via mains. Additionally, in the technique, battery's charging limits are also considered and are kept as protective overriding functions. For example, if battery is fully charge, charging via Mains and Solar is stopped completely irrespective to battery conditions. Since the commonly used set points for these overriding functions are also important for determination of BC, Modes are briefly discussed in the following section.Fig.1 show the flow chart of our system mechanism. In that depending on battery voltage action will takes place. Peak usage time is the time in which battery usage is more. In prediction algorithm, First check battery voltage if battery voltage is less than low voltage (low voltage mode). And solar voltage is above the sufficient level then it will charge the battery from solar voltage otherwise charging will takes place via AC mains. Another condition is depending on peak usage time mechanism. If PUT is present, battery voltage is greater than sufficient voltage then our system will work in Power saving mode else it will again check mains present or not. If mains is present then it will working in Bypass mode else it will working in Override mode. If PUT is absent, mains is absent and battery voltage is greater than sufficient voltage then system will working in power saving mode else battery voltage checking takes place depending on that mode switching will takes place. In mode switching, driving circuitry is present it will take care of our system. If solar voltage not sufficient then appropriate switching will takes place and situation will handled by controller.

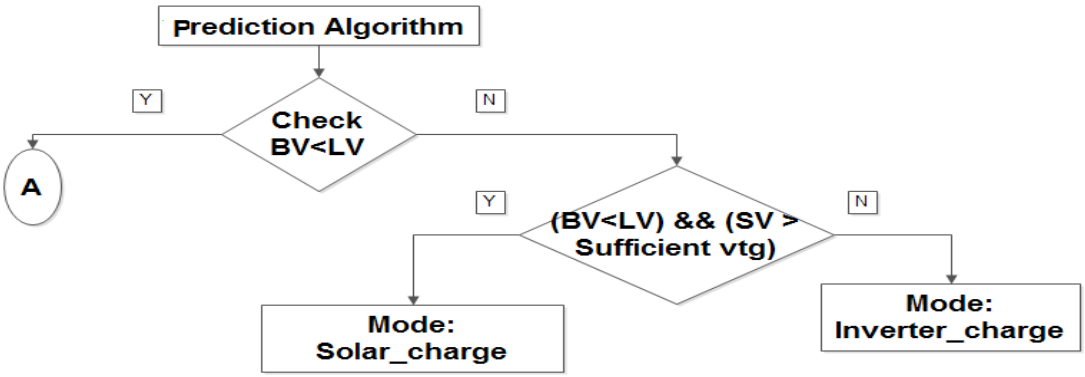

BV: Battery Voltage

LV: Low Voltage

SV: Solar Voltage

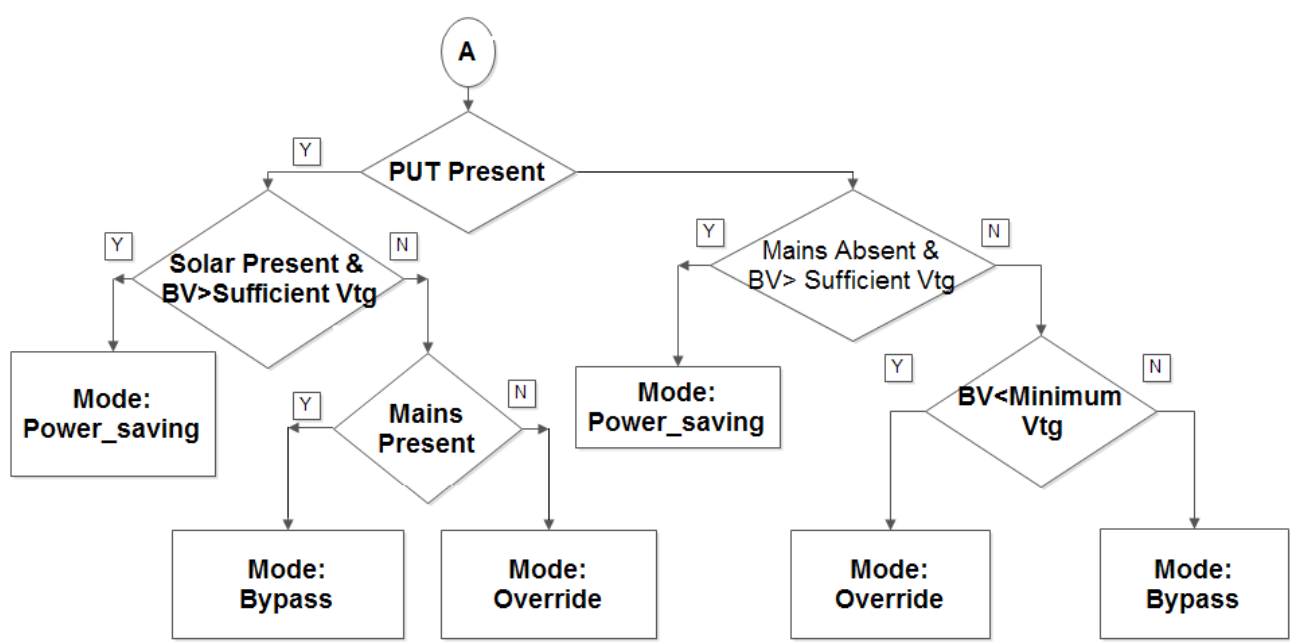

Fig. 1: Flowchart of prediction based algorithm 
Design of peak usage time and prediction algorithm based battery charging technique

\begin{tabular}{|c|l|l|l|}
\hline \multicolumn{5}{|c|}{ MODE } & \multicolumn{1}{|c|}{ Mode Description With battery voltage } & Operation \\
\hline Sr.No. & \multicolumn{1}{|c|}{ MOperation in 5 Modes } \\
\hline 1 & $\begin{array}{l}\text { SunTap } \\
\text { /Power_saving }\end{array}$ & $\begin{array}{l}\text { Battery level is greater than } 12.5 \text { and } \\
\text { solar present and PUT ON }\end{array}$ & $\begin{array}{l}\text { Inverter forcefully Off, } \\
\text { Load drive through Battery } \\
\text { and Solar charging }\end{array}$ \\
\hline 2 & Bypass & $\begin{array}{l}\text { Battery level is less than 12.5 and greater } \\
\text { than 10.5 and mains on, battery will charge } \\
\text { through inverter }\end{array}$ & $\begin{array}{l}\text { Inverter Forcefully Off, } \\
\text { Load drive through mains } \\
\text { solar charging }\end{array}$ \\
\hline 3 & Inverter Charge & Battery level is less than 10.5 , and solar absent, & $\begin{array}{l}\text { Inverter On, drive load from } \\
\text { mains, charge battery by } \\
\text { inverter }\end{array}$ \\
\hline 5 & $\begin{array}{l}\text { Inverter solar } \\
\text { charge }\end{array}$ & Battery level is less than 10.5 , and solar is present & $\begin{array}{l}\text { Inverter Off, drive load by } \\
\text { mains ,charge battery by solar }\end{array}$ \\
\hline & Override mode & Battery level is less than 10.5 ,and solar is Absent & $\begin{array}{l}\text { Inverter Off, drive load by } \\
\text { mains ,charge battery by } \\
\text { Mains }\end{array}$ \\
\hline
\end{tabular}

Table 1: Modes of System operation

III. Implementation On Hardware

In this section hardware designs for implementation of the prediction based algorithm are briefly discussed. Design is considered to show how the technique can be implemented in simple way. Fig.2. Show the block diagram of system. In this system sensing circuit, switching circuit, microcontroller section play important role [6]. The mode switching is based on solar voltage and battery. Sensing circuit sense battery as well as solar voltage and provide this data to controller. Controller will calculate the information with predefined data and save all this information with time into EEPROM for future use. Predefined data such as battery Ah capacity, peak usage time, grid voltage and frequency. With the help of this calculation controller send signal to switching circuit. LCD and LED are used for the indication purpose. Buzzer will indicate the critical situation. The RTC provides a time reference to an application running on the device. The current date and time is tracked in a set of counter registers that update once per second. The time can be represented in 12-hour or 24-hour mode. The RTC can interrupt the CPU every time the calendar and time Registers are updated. This will interface our project with the help of I2C bus. EEPROM stands for Electrically Erasable Programmable Read-Only Memory and is a type of non-volatile memory. This is used in our project to store the configuration and also project status for every 60minute. The UART performs serial-to-parallel conversion on data received from a peripheral device or a modem, and parallel-to-serial conversion on data received from the CPU.it is used for run time testing purpose.

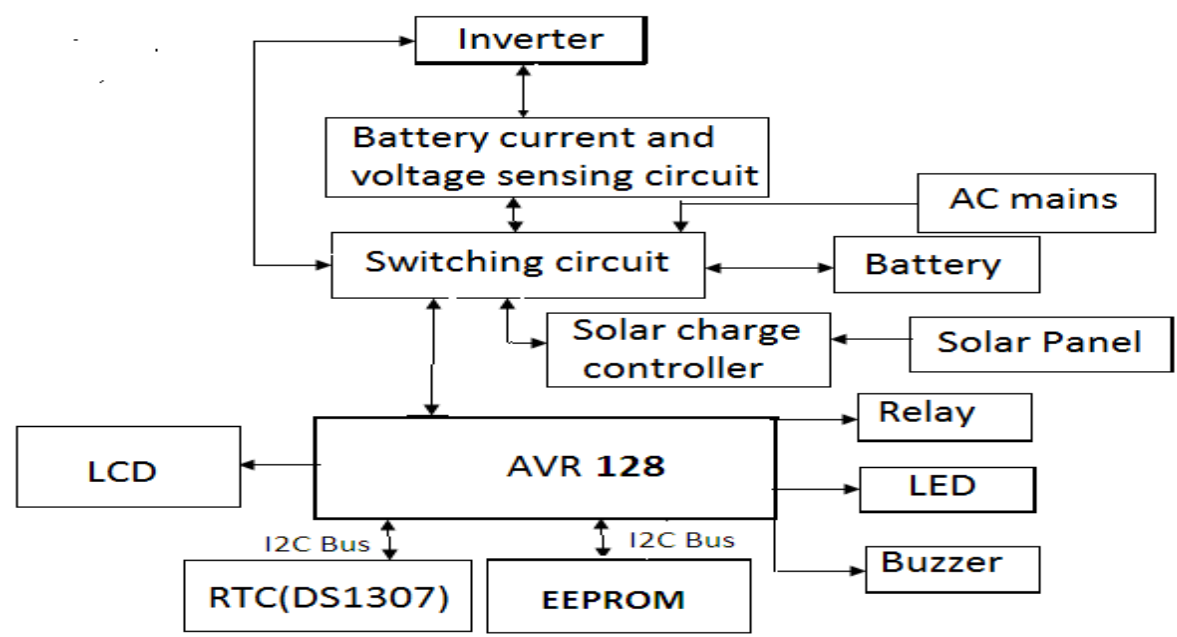

Fig.2. Block diagram of prediction based algorithm

We are dealing with Ac so hardware design is very important. One of the biggest challenges in this system is sensing of battery voltage and depending on that calculates the efficiency. For battery sensing separate circuit is designed. Because battery voltage is variable it will suddenly change its state at the time of connecting load and disconnecting load so we have to take care at the time of battery sensing circuit implementation. This voltage measurement data is useful at the time of battery calculation. Main part of system is switching circuit. The total operation of system is depends on this circuit. Part of circuit is shown in fig.6. In this BJT are used for 
switching purpose. SPDT relay are used in switching circuit .Main use of relay is to switch the system mode according to battery voltage. System needed 5V so regulated power supply is design. And for AC indication separate buzzer driver circuit is used. Opto-isolator's driver circuits are used for protection of controller because we are dealing with mains. In this we are using LED driving circuit and switching circuit. LED driving circuit used to indicate the mode of the system and mains availability.

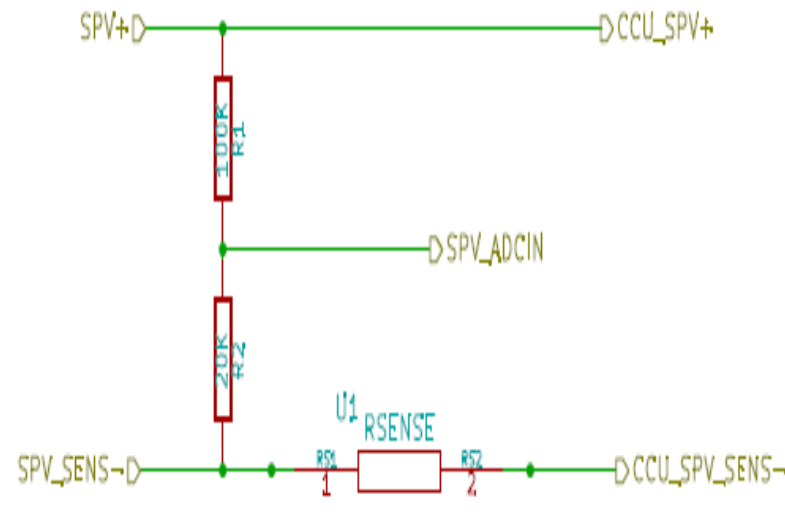

Fig.3.Circuit diagram of sensing of battery voltage

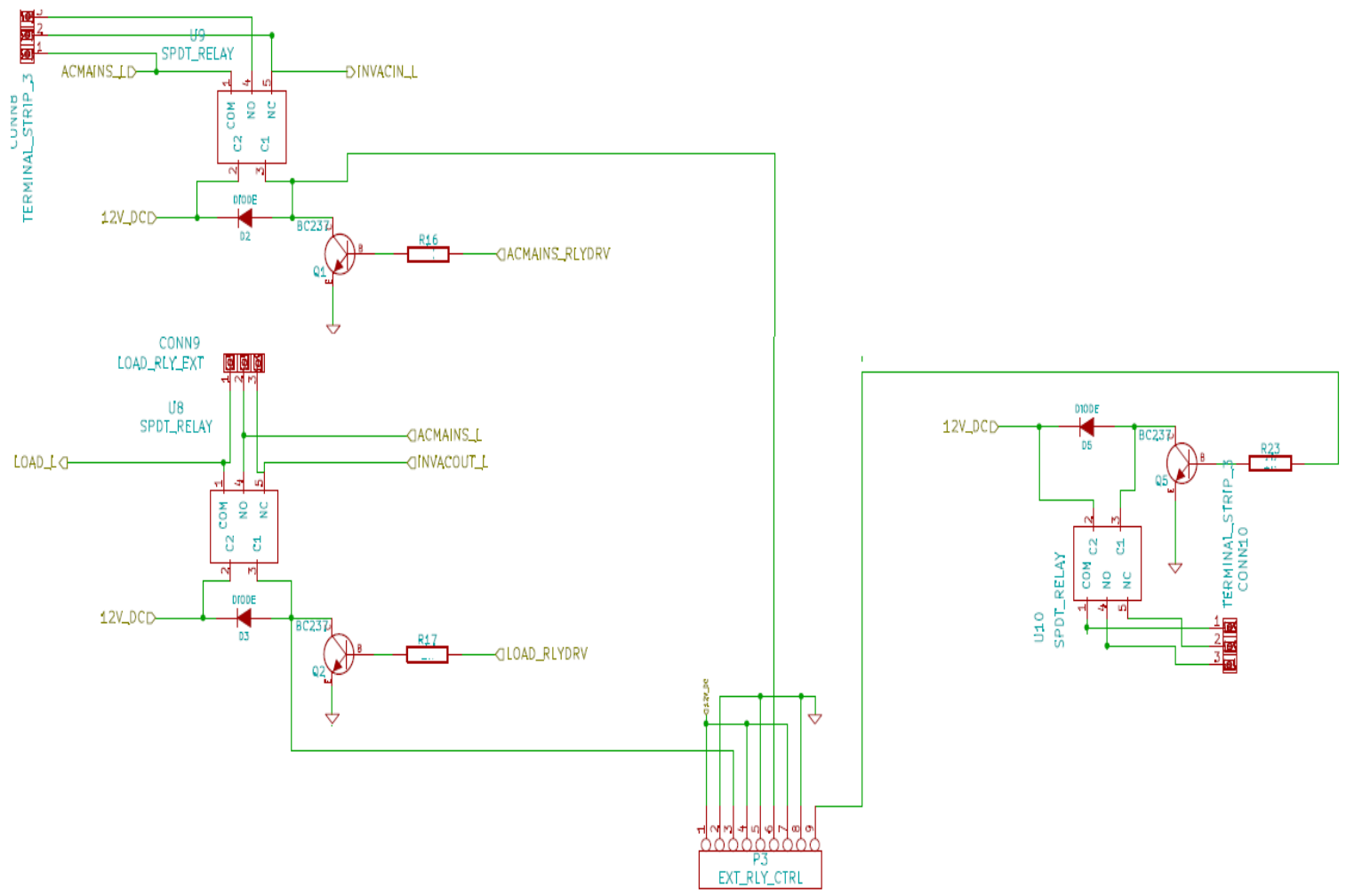

Fig.4. Circuit diagram of switching circuit

\section{Results And Discussions}

In order to test Prediction Based System (PBS), i.e. the system designed with the proposed technique, it was programmed in $\mathrm{C}$ programming language and simulated in Proteus 7.4. Prediction based and peak usage time mechanism is use in this system. It focuses on how to control and manage the solar power. Simulation is shown in below figure. Read input voltage and this data are display on LCD. Depending on it switching of relay take place. 


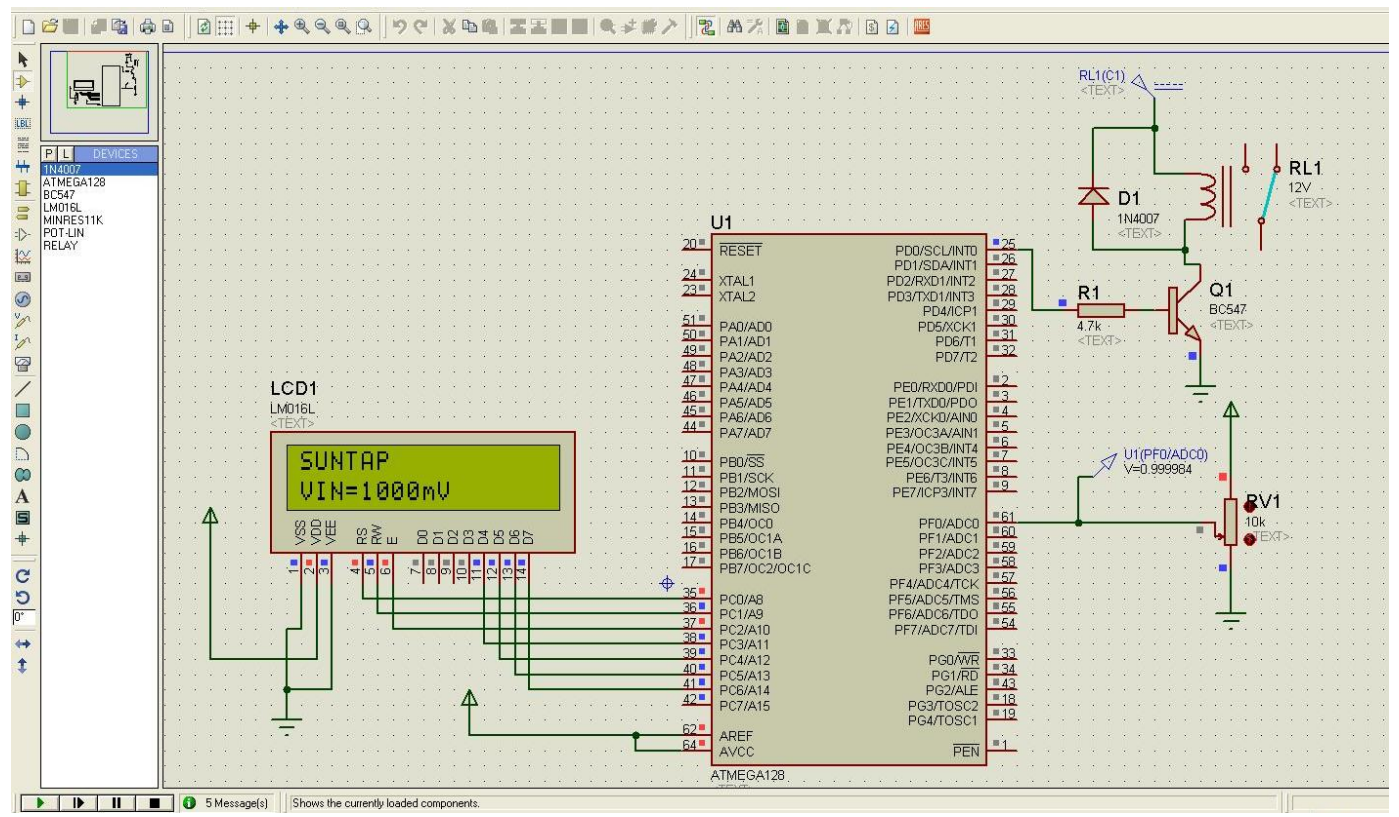

Fig5. Simulation setup for Battery charging switching diagram

\section{Choosing the correct number of battery}

Most batteries' A.H. capacity is stated for the 20-hour rate of discharge. This means that a battery has a 100 A.H. capacity if it is discharged over 20 hours, or at about 5 Amps-per-hour (100 A.H. / 20 hours $=5$ Amps DC). However, this same battery would last only one hour if the discharge rate was 50 Amps-per-hour (50 Amps DC x 1 hour $=50$ A.H.) because of the high rate of discharge. The more deeply the battery is discharged on each cycle, the shorter the battery life will remain. Therefore, using more batteries than the minimum will result in longer life for the battery bank. Keep in mind that batteries lose capacity as the ambient temperature lowers.

\begin{tabular}{|c|c|}
\hline Battery Capacity(A.H) & Hours of Discharge \\
\hline 100 & 20 \\
\hline 90 & 10 \\
\hline 87 & 8 \\
\hline 83 & 6 \\
\hline 80 & 5 \\
\hline 70 & 3 \\
\hline 60 & 2 \\
\hline 50 & 1 \\
\hline
\end{tabular}

\section{Conclusion}

This paper has presented a peak usage time and prediction based algorithm for battery charging in solar home systems. The algorithm enables smart battery charging decisions based on calculated prediction of battery future state to utilize solar energy, improve battery life and less Mains electricity while maintain high reliability. The main improvement in the system will be done in the calculation efficiency of charging and discharging of batteries. The algorithm is flexible in this respect as such changes can be easily adjusted in technique. Some theories, which give simple empirical relationship between capacity of battery and discharge rate, can be more accurate in this regard. Also, store all relevant data (such as charge/discharge rates, solar availability, load requirement, peak usage time etc.) of one day and utilizing the data for the next day while making calculations in controller. Since the data of days will change according to the climate. But we can change setting according to our use. But most of the time data store in sequence will have similar pattern, repetition of the above process could yield more effective result. However, more time and research are required to verify that the new techniques and algorithm will be more effective for our system.

\section{Acknowledgements}

The authors gratefully acknowledge all those who have helped in making of this review successfully. As this review process of paper was carried out at G.H. Raisoni Institute of Engineering \& Technology Pune. So, special thanks to Head of E\&TC Department, Principal and management of GHRIET, Pune. 


\section{Journal Papers}

\section{References}

[1]. K.Kavitha , T.Deepa , Dr. A. Ebenezer Jeyakumar, Microcontroller based Optimal Battery Charging in a Solar Powered Robotic Vehicle, International Journal of Scientific and Research Publications, Volume 4, Issue 7, July 2014 ,2250-3153

[2]. Masudul Haider Imtiaz, Mst.Rumana Aktar Sumi, Design \& Implementation of an intelligent solar hybrid inverter in grid oriented system for utilizing PV energy , International Journal of Engineering Science and Technology Vol. 2(12), 2010, 7524-7530

[3]. Samantha J. Gunter, Khurram K. Afridi,, and David J. Perreault, Optimal Design of Grid-Connected PEV Charging Systems With Integrated Distributed Resources , IEEE TRANSACTIONS ON SMART GRID, VOL. 4, NO. 2, JUNE 2013

[4]. Mrs Jaya N. Ingole, Mrs Dr. Madhuri A. Choudhary, and Dr. R.D. Kanphade, Pic Based solar charging for battery, International Journal of Engineering Science and Technology (IJEST), Vol. 4 No.02 February 2012

[5]. E. Koutroulis, K. Kalaitzakis, and N. C. Voulgaris, Development of a microcontroller-based, photovoltaic maximum power point tracking control system, IEEE Trans. Power Electron., vol. 16, no. 1, pp. 46-54,Jan. 2001.

[6]. W.Xiao,N.Ozog R,W.G.Dunfold (2007), Topology Study of Photovoltaic Interface for Maximum Power Point Tracking, IEEE Transaction on Industrial Electronics, vol. 54, no. 3, june 2007

[7]. A.Harish1, M.V.D.Prasad2, Microcontroller Based Photovoltaic MPPT Charge Controller, International Journal of Engineering Trends and Technology (IJETT) - Volume 4, Issue 4, April 2013

[8]. S. Zheng and L. Wang, Research on charging control for battery in photovoltaic system, 6thIEEE Conference on Industrial Electronics and Applications (ICIEA), 2011.

[9]. Samuele Grillo, , Mattia Marinelli, Stefano Massucco, and Federico Silvestro, Optimal Management Strategy of a Battery-Based Storage System to Improve Renewable Energy Integration in Distribution Networks, IEEE TRANSACTIONS ON SMART GRID, VOL. 3, NO. 2, JUNE 2012

[10]. Tom'as de J. Mateo Sanguino and Justo E. Gonz'alez Ramos, Smart Host Microcontroller for Optimal Battery Charging in a SolarPowered Robotic Vehicle, IEEE/ASME TRANSACTIONS ON MECHATRONICS, VOL. 18, NO. 3, JUNE 2013

[11]. K. Balasubramanian, and A.Cellatoglu, Improvements in Home Automation Strategies for Designing Apparatus for Efficient Smart Home, IEEE Transactions on Consumer Electronics, Vol. 54, No. 4, NOVEMBER 2008 